\title{
UN ACERCAMIENTO AL CUENTO INFANTIL DESDE LA PERSPECTIVA DE GÉNERO. ESTEREOTIPOS EN EL CUENTO INFANTIL
}

¿Cuáles son los papeles que desempeñan cada una de las mujeres que son parte de la sociedad? ¿Cómo exige un hombre que se comporte una mujer? ¿Habrán cambiado los estereotipos femeninos y masculinos que muy claramente nos presentan los cuentos? ¿Seguimos propiciando como personas los estereotipos? ¿Se está dando la inversión tanto en los cuentos como en nuestras vidas?

A partir de mito griego de la Medusa, se introduce el tema del género y la literatura, sobre todo en aquella que se reconoce como literatura infantil. Desde la perspectiva de género, se pueden tratar diferentes tópicos, en este caso, el artículo se centra en los estereotipos y confrontan los que se derivan de la mujer ángel y la mujer demonio.

A lo largo de la historia, la elaboración del mundo simbólico, del significado y del sentido han estado en las mentes de los varones, los que han configurado una representación del mundo a su imagen y semejanza. Son ellos el prototipo, patrón y medida de lo existente.

En los cuentos infantiles podemos ver claramente los estereotipos impuestos por la cultura patriarcal; pero también, cómo algunos de ellos son capaces de subvertir el orden estaablecido. Lo más importante es que la lectura de cuentos infantiles y de la literatura en general, sine para movernos y conmovemos comolectores; paraque nos marque, porque nos interpela.

\section{Nuria Méndez Garita*}

\begin{abstract}
What is the role of each woman in society? What are a man's demands in regards to a woman's behavior? Have the feminine and masculine stereotypes clearly presented to us in stories changed? Are we still, as humans, favoring stereotypes? Is inversion still taking place in both, stories and real life? The Greek myth about Medusa introduces the topic of gender and literature, especially in children's literature. Different topics may be discussed from a gender perspective; in this case, the article focuses on stereotypes: those derived from the woman as an angl and the woman as the devil. Throughout history, the world of symbolism, of meaning and sense has been present in the minds of men, who have represented the world to theirvisible reflection. They are the prototype, model and size of that which exists. In children's stories, we can clearly see the stereotypes imposed by the patriarchal culture; however, we can also see how some of them are able to subvert a pre-established order. What is most important is that reading children's stories and literature in general, enables us to move and be moved as readers; it leaves a trace, because it questions us.
\end{abstract}

* Filóloga, graduada en la Universidad de Costa Rica. Académica de la División de Educación rural, CIDE-UNA, desde el 2001. Tiene a su cargo los cursos de Literatura Infantil en esta unidad académica y la producción de material de apoyo para docentes rurales en el área de Español. Además, ha sido profesora de Español en varios colegios de Cartago y San José. 
Esta es la historia de una mujer, que al nacer estaba cubierta con todos los encantos personales que puedan imaginarse y admirados, todos aquellos que la veían la felicitaban y alababan su hermosura, en especial, sus cabellos. Como era de esperarse, tenía muchos pretendientes. Sin embargo, se atrevió a afirmar que era superior a cualquiera otra mujer, incluso, a una diosa. Esta mujer se llamaba Medusa y era la única mortal, entre tres hermanas; cuenta la historia que su belleza le sirvió para afirmarse a sí misma como mujer y por eso la calificaron como terriblemente engreída. Una diosa celosa, Atenea, la convirtió en una horrible mujer; le transformó en serpientes sus cabellos, cubrió su cuerpo con escamas, le dio dos alas en la espalda, desfiguró su rostro, le agrandó los dientes y los convirtió en colmillos y la obligó a vivir siempre con la lengua afuera. Sin embargo, tenía un don: ningún hombre podía mirarla a los ojos, pues su mirada los dejaba petrificados y esto les provocaba un terrible temor.

Tiempo después, un joven caballero, Perseo, organizó una expedición para ir en su busca y matarla. Como ayuda, recibió el escudo de Atenea, la espada de Hermes y su talar y un casco dado por Hades que le permitían hacerse invisible. Perseo atravesó el océano y la halló durmiendo, así como a todas sus culebras. Entonces, movido su brazo por Atenea, ya que no podía mirar a Medusa, le cortó la cabeza y la mató. Perseo escapó sin problemas. Como resultado de la muerte de Medusa, nació Pegaso. Más tarde, el héroe utilizó la cabeza de Medusa para defenderse del temido gigante Atlas, pues se la lanzó y este quedó convertido en montaña. La sangre de Medusa, según cuenta el mito, tenía cualidades mágicas: la que brotó del lado izquierdo era un veneno mortal y la del lado derecho curaba y resucitaba al que la bebiera. Por otro lado, su cabello hacía huir al ejército más numeroso. Para muchos mitólogos, Medusa simbolizaba el carácter maligno de la mujer y representaba a la mujer-demonio, a la madre que da la muerte, al lado oscuro de la feminidad. Ese lado oscuro se refiere a la intimidación que provoca la Medusa en los hombres, pues solo ellos quedaban petrificados por su mirada. Por eso, había que acabar con ella.

Sirva el mito griego para introducir este tema del género y la literatura, sobre todo el cuento que conocemos como infantil. Desde la perspectiva de género, se pueden tratar diferentes tópicos, en este caso, nos centraremos en los estereotipos y confrontaremos aquellos que se derivan de la mujer ángel y la mujer demonio.

El sexo es una categoría biológica. Según esta los seres humanos, de acuerdo con diferencias fisiológicas y morfológicas, pueden ser clasificados como hembras y machos. El género es una construcción sociocultural que define diferentes características emocionales, intelectuales y de comportamiento entre las personas, por el hecho de ser hembras o machos. Distinguir entre sexo y género 
es útil para diferenciar lo que es "natural" (lo biológico) de aquello que no lo es (lo cultural). Hombre y mujer son socializados en forma distinta. Se espera de ambas actividades, funciones, comportamientos, sentimientos, actitudes y aún valores no solo diferentes sino, en muchos casos, opuestos. La internalización de estos modelos (con base en un premio-castigo) logra el objetivo de control social sobre el ser y quehacer femeninos fundamentalmente, lo cual tiene también un alto costo para el ser y quehacer masculinos. Hombres y mujeres socializados, discriminatoriamente, en todos los sistemas en los cuales participan desde su nacimiento, generan identidades masculinas y femeninas incompletas y estereotipadas, las cuales permiten la reproducción ideológica de los modelos de "ser" y "actuar", haciendo invisibles (aún para las propias protagonistas), las inequidades, discriminaciones y exclusiones.

El género es justo ese instrumento cultural capaz de alterar y vehicular las motivaciones fundamentales, de dirigirlas hacia diferentes procesos de socialización ligados al establecimiento y mantenimiento del poder. Por ello, el género es símbolo de autoridad, es decir, representa la autoridad y, al mismo tiempo, realiza ese poder, pero más que nada, educa en ese poder. Así, el poder es el símbolo de la diferencia absoluta. Si el género simboliza el poder, es porque el poder simboliza la diferencia. Si el género ha sido una herramienta fundamental en los ritos de subordinación y dominio, es porque la importancia de la sexualidad prevalece sobre la personalidad y la actividad social.

La sociedad en la que vivimos es de carácter patriarcal, entendiendo por patriarcado:

La institucionalización del dominio masculino sobre mujeres y niños/ as en la familia y la extensión del dominio masculino sobre las mujeres a la sociedad en general. Implica, que los hombres ostentan el poder en todas las instituciones importantes de la sociedad y que las mujeres son privadas de acceso a ese poder.

Y agregamos que no implica que las mujeres no sean capaces de ejercer un poder, de definirse, de hablar.

En un discurso patriarcal, una mujer es lo que el hombre dice de ella, con lo cual, se le priva del derecho a desarrollar y afirmar la propia imagen. (Macaya,1997 p. 30)

A lo largo de la historia, la elaboración del mundo simbólico, del significado y del sentido ha estado en las mentes de los varones, los que han configurado 
una representación del mundo a su imagen y semejanza. Son ellos el prototipo, patrón y medida de todo lo existente. De esta forma, se ha establecido el paradigma patriarcal -desde el Pater familias- como el paradigma de todos los paradigmas, en cuanto que los valores de género masculinos sustentan todas las interpretaciones filosóficas, científicas o religiosas de la realidad.

El género queda inscrito históricamente conforme el cuerpo del hombre se fue convirtiendo en modelo de lo humano. Si pensamos en la tradición judeocristiana de la costilla de Adán, podemos suponer que esta estructura oculta un aparato de dominación: es el más débil, quien más necesita dominar. En la inscripción histórica del género, se vislumbra una total inversión simbólica: el carácter innecesario, precario, incompleto, emocional, pasivo; es decir, toda la precariedad orgánica y psicológica que el hombre no reconoce para sí, queda desplazada y proyectada sobre el cuerpo de la mujer. (www.estudiosonline.net/ text/moraza.html)

El enigma de la feminidad ha puesto pensativos a los hombres de todos los tiempos. Remite a la diferencia de los sexos y a la experiencia histórica y cultural que de ella se tenga. Para Simone de Beauvoir (1998), la historia ha demostrado que los hombres siempre han tenido los poderes concretos; desde los inicios del patriarcado ellos han creído útil y conveniente mantener a la mujer como dependiente y han establecido sus códigos contra ella. Estos códigos la someten y la invisibilizan. El hombre ha construido a la mujer no solo con la imagen que el mismo desea, sino que esa construcción también se ha traducido en palabra escrita, en estereotipo, en conducta que tiene que seguir, en una norma preestablecida.

Para entender la identidad femenina, hay que tener en cuenta que todo el pensamiento occidental está fundamentado en una serie de dicotomías: mujer versus hombre, naturaleza versus cultura, privado versus público, reproducción versus producción, intuición versus razón, cuerpo versus intelecto.... etc. Esta visión dicotómica de la realidad conlleva una jerarquización de las partes implicadas y la asociación de la mujer con los términos menos prestigiosos de esa realidad dual, es decir, con la naturaleza, con el ámbito privado, con la reproducción, con la intuición y con el cuerpo, en tanto que al varón se le asocia con la cultura, con la esfera pública, con la producción y la razón.

Esta consideración dicotómica y jerárquica del mundo favorece, además, una concepción esencialista de los sexos, haciendo derivar la división sexual del trabajo "naturalmente " de las diferencias biológicas entre los sexos. Esa división sexual del trabajo se consagra con la implantación del sistema industrial, con el profundo hiato introducido por el capitalismo entre el ámbito público y el ámbito privado. A partir de este momento, se sanciona e institucionaliza la dedicación del 
varón al mundo profesional, laboral y político y el confinamiento de la mujer en el mundo doméstico y privado. Esta situación da inicio a los estereotipos.

$\begin{array}{ll}\text { MUJER } & \text { HOMBRE } \\ \text { Naturaleza } & \text { Cultura } \\ \text { Privado } & \text { Público } \\ \text { Reproducción } & \text { Producción } \\ \text { Intuición } & \text { Razón } \\ \text { Cuerpo } & \text { Intelecto } \\ \text { Adentro } & \text { Afuera }\end{array}$

Muchos de estos prejuicios y mitos son tan antiguos como la propia filosofía o la propia capacidad humana de justificación y explicación del mundo y, aunque algunos de ellos están desbancados a nivel científico, persisten sin embargo en el imaginario simbólico. Todos ellos consideran a la mujer como un ser deficitario, carente y mutilado y/o siempre identifican el ser mujer con el ser madre. Si una mujer no se identifica con ellos, entonces, surgen la mujer ángel o demonio.

Según Emilia Macaya (1997:66), “ha pretendido el sistema patriarcal desarticular el hacer femenino estereotipado a la mujer ángel o como demonio, en dos polos opuestos, la aíslan del espacio intermedio existente entre ambos reinos: el mundo habitual del actuar cotidiano y público, como ámbito del quehacer cultural."

No es de extrañar, entonces, que en algunos escritos se satirice a la mujer con arquetipos detestables, demoníaca, histérica, por ejemplo, o bien, con otros apelativos como alacrana, culebrón, fierísima.

$\mathrm{El}$ arquetipo de identidad femenina es el de un ser de relaciones que se constituye a partir de los roles de madre y esposa. Las virtudes que se valoran como importantes para realizar esta labor y alcanzar el reconocimiento social son: la abnegación, la sumisión, la capacidad empática, la resignación, la paciencia, y la vivencia bajo una ética de dolor y sacrificio. El concepto de mujer subyacente a estos valores es el de la mujer pasiva, dependiente y asexuada que ha sido expropiada de su cuerpo, de su sexualidad y de su energía vital y creativa.

Para el hombre, la mujer ha de ser un objeto y su esencia radica en el eterno femenino: mujer ángel del hogar. De no ser así, será la mujer fatal, madrastra, bruja, prostituta o demonio; no hay punto intermedio, lo cual es injusto.

De acuerdo con Yadira Calvo "Cuando un grupo oprime al otro o domina a otro, tiende a justificar tal situación de desigualdad, recurriendo a una historia que se remonta a los orígenes o a pseudoexplicaciones que invocan una concepción particular del hombre y de la sociedad." (1990 p. 27). 
-MUJER ÁNGEL

-Abnegación

-Sumisión

-Asexuada

-Resignación

-Paciencia
-MUJER EXPROPIADA

-Autonomía

- Cuerpo

-Sexualidad

-Liberación

-Empatía

La mujer ángel es aquella que defiende el sistema establecido; es espejo del orden masculino; es pasividad porque es inmóvil; inmovilidad cercana a la muerte; es el ideal absoluto y además, su función es perpetuar el nombre del padre: crianza y ambiente doméstico. Es la domesticada.

Y muchas veces hasta las Hadas les dan obsequios: "Fue una fiesta magnifica y, al final, las hadas dieron sus regalos a la niña: una hada le dio la bondad, otra la belleza; otra, la riqueza. Así fueron todas las hadas regalando a la niña las mejores cosas de este mundo." (La bella durmiente del bosque, 107) Indudablemente, este proceso de idealización de lo femenino es un mecanismo ideológico que ayuda a marginar a la mujer. La ideología, dice Helene Cixoux, es una membrana que cubre y encumbre, y por lo tanto, no permite ver la conformación real. Porque "el sistema patriarcal...elabora una imagen de creación literaria eternamente subordinada a lo masculino, desde las originales fuerzas asociadas a Dios" (Macaya,1992 p. 45).

Carmen Lyra, en su cuento Escomponte perinola, refleja claramente la estructura patriarcal desde su origen centrado en la Ley del Padre, hasta el dominio que debe tener el hombre sobre la mujer y cuál es el castigo que tendría esta, si no se ajusta al sistema establecido; castigo por lo demás doloroso:

- "hombre, Juan, ¿qué es eso?

Levantó los ojos y allí estaba tatica dios en persona, con un saco a la espalda, mirándolo, entre malicioso y compasivo.

¿Y eso qué es, Juan? ¿mariquiando como las mujeres? Se veía que le quería meter ánimo.

- ¿Pues no ves, señor mío Jesucristo, que con el burro también me fue mal? Mientras la cosa era afuera, funcionaba muy bien, pero en cuanto llegué a mi casa, y había que enfrentarse a mi mujer, ;adiós mis flores! -Pues hijo, yo lo que encuentro es que vos no te das a respetar de tu mujer ni de tus hijos y eso va contra la Ley de Dios. Allíquien debería tener los pantalones es tu mujer...vos debés amarrarte esos calzones, Juan, si no querés que tus hijos acaben encaramársete encima y tu mujer te ponga grupera." (Lyra, p.42) 
La deconstrucción de esta figura se realiza a partir de varios niveles que se oponen a las características del arquetipo: autonomía, cuerpo y sexualidad. Ahí se ubica la mujer demonio, aquella que se autodefine, la que subvierte el orden, la que se puede escapar de la autoridad; por eso, es la depositaria de un cúmulo de amenazas y males que delatan su desobediencia. Es la "otredad maldita de la carne."

Porque las brujas, histéricas y demoníacas son capaces de hablary defenderse y al igual que la Medusa, no son siempre feas físicamente. He ahí parte del problema. "la belleza como poder seductory puesto que la mujer representa tanto las delicias comolos peligros de la carne, debe ser dominada y poseída para que de esa forma, puesta al servicio del hombre, no amenace su vigor, ni su imperio mediante inconvenientes tentaciones. "(Macaya, 1997 p. 66) Por esta razón hay que matar a Medusa; por eso, Juan Cacho tiene la autoridad divina para golpear a su mujer y que esta sea silenciada.

Eso le pasó a Casandra y a Helena en Troya; eso le pasó también a María Magdalena. Y en los cuentos infantiles, a la madrastra de Blanca Nieves. Casandra vivió recluida, no la quisieron escuchar y además, visualizaba el futuro; Helena se atrevió a abandonar a Menéalo y llevó sobre sus espaldas la justificación de una guerra que de previo ya había sido planeada. María Magdalena, discípula de Jesús, lo acompañó hasta su muerte y fue a ella a quien él se le presentó de primero una vez resucitado; sin embargo, la recordamos como la prostituta arrepentida.

Y en Blanca Nieves, "El rey se casó con otra mujer que era muy hermosa, pero orgullosa y presumida" y como dicen Gilbert y Gubar (1984: 36) en Blanca Nieves se "dramatiza la esencial, pero equívoca relación entre la mujer ángel y la mujer monstruo.. Blanca Nieves, a quien Walt Disney tituló Blanca Nieves y los siete enanos, debería ser llamada Blanca Nieves y su Malvada Madrastra, porque la acción central del cuento es una acción que surge de la relación entre dos mujeres: una hija, la otra una madre; la una dulce, ignorante, pasiva; la otra astuta y activa; la una suerte de ángel, la otra una bruja indiscutible." ${ }^{1}$

En Escomponte perinola, la mujer se había liberado, era la paloma que se convirtió en sapo, la que era una chompipona, una gallota, un toro guaco, un culebrón y más brava que un solimán, porque era fierísima. Con esos calificativos, no cabe en nuestra mente verla como algo hermoso y se nos diluye la imagen de mirarla como persona que se define a sí misma. Sin embargo, era mujer y se defendía.

Calificarlas como brujas es un "mecanismo que obedece al propósito manifiesto y mantenido de acallar la voz de las mujeres.” (Calvo, 2002 p. 26). Preguntémonos ¿por qué se da la cacería de brujas?

A lo femenino se le atribuyen arbitrariamente caracteres psicológicos entre los que predomina la emotividad, la dependencia, el hecho de ser despilfarradora, sumisa, sensible y habladora. Por otra parte, lo masculino está asociado con el

1 Traducción propia 
liderazgo, el poder, la autoridad y la toma de decisiones y cuando una mujer opta por este segundo tipo de cualidades, entonces, es un demonio, una bruja y no debe sobresalir en campos económicos, políticos o científicos. Aunque tenga razón e inteligencia, se la minimiza y se la excluye.

No se puede abordar la cuestión del alma femenina moldeando a la mujer de manera que se adapte a una forma más aceptable según la definición de la cultura que la ignora, y tampoco se puede doblegar a una mujer con el fin de que adopte una configuración intelectualmente aceptable para aquellos que afirman ser portadores exclusivos del conocimiento. (Pinkola, 2003 p. 16).

En los cuentos podemos ver claramente estos estereotipos impuestos por la cultura patriarcal. Cabe decir también que algunos de ellos son capaces de subvertir el orden. Veamos unos ejemplos:

\begin{tabular}{|l|l|l|}
\hline \multicolumn{1}{|c|}{ Estereotipo } & \multicolumn{1}{|c|}{ Femenino } & \\
\hline $\begin{array}{l}\text { Cognitivos y de } \\
\text { personalidad }\end{array}$ & $\begin{array}{l}\text { Ingenuidad, intuición, } \\
\text { poco inteligente, } \\
\text { inconsciente, voluble }\end{array}$ & $\begin{array}{l}\text { Blanca Nieves, Caperucita } \\
\text { Piel de Asno } \\
\text { La princesa }\end{array}$ \\
\hline Personaje femenino & $\begin{array}{l}\text { Ternura, cuidada por... } \\
\text { debilidad, } \\
\text { generosidad, } \\
\text { obediencia, } \\
\text { dependencia, } \\
\text { miedo, } \\
\text { falta de control }\end{array}$ & $\begin{array}{l}\text { La Bella Durmiente } \\
\text { Cenicienta }\end{array}$ \\
\hline $\begin{array}{l}\text { Estereotipo (cuento) } \\
\text { Baperucita }\end{array}$ & $\begin{array}{l}\text { Astucia, con gran } \\
\text { agilidad mental, fuerza }\end{array}$ & $\begin{array}{l}\text { Lobo } \\
\text { Cazador } \\
\text { Leñador }\end{array}$ \\
\hline $\begin{array}{l}\text { La princesa } \\
\text { La Bella Durmiente } \\
\text { Cenicienta }\end{array}$ & $\begin{array}{l}\text { Fortaleza, } \\
\text { Independencia, } \\
\text { Valentía } \\
\text { Agresividad, } \\
\text { Racionalidad, } \\
\text { Eficiencia, } \\
\text { Perfección }\end{array}$ & $\begin{array}{l}\text { Rey Picodeloro, } \\
\text { Príncipe }\end{array}$ \\
\hline
\end{tabular}


¿Qué pasa cuando un personaje, sea niño, niña o mujer, trata de subvertir el orden, o bien, participar del mundo común y corriente, de lo cotidiano, cuando externa su opinión? Simplemente que es silenciado y marginado y como un patito feo, excluido.

En el cuento el Rey Picodeloro, la hija del rey era hermosa, pero también orgullosa y altanera y ningún pretendiente le parecía lo bastante digno; por ello, gozaba con decirles los defectos. Como esto iba en contra de las órdenes de su padre, este decide regalarla, cual objeto, al primer mendigo que apareciera, signo inequívoco de degradación. Ese mendigo la pone a prueba y por supuesto, la princesa falla en las cosas domésticas: no teje, no está callada, no cocina. Conocemos el final: el mendigo era el príncipe, uno de los ofendidos y ella con la lección aprendida, se calla y así debe vivir feliz para siempre.

Básicamente, Escomponte perinola tiene el mismo orden de ideas: una mujer, sin nombre también, enfrenta a su esposo; para dominarla. El esposo tiene la autorización de golpear y meter en cintura, no solo a ella, sino que a los hijos también.

En El Rey que desea escribir un cuento, queda claro que el poder de la palabra le pertenece al hombre, que aunque la mujer sea prudente y sabia, como buena y preciosa, no puede ni debe tomar decisiones. Por eso, hay que acallarla.

Las dos se acercaron al balcón a ver qué había escrito el Rey.

- ¿Terminaste el cuento, papá?-le preguntó su hija con dulzura-.

- Todavía no, pero espero hacerlo pronto.

-¿Y qué vamos a hacer?-dijo la Reina con acento preocupado-El

Consejero Real nos ha informado que el país está en quiebra. Hay escasez de alimentos y nadie quiere trabajar. ¿Por qué no escribes otro día y atiendes ahora este gran problema?

- CCómo puedes decirme semejante cosa? Lo que estoy haciendo es muy importante para mí...

La reina agachó la cabeza, no dijo nada y salió enseguida con su hija. (Rios, p. 9).

El Rey no permitirá que su reino, pase a manos de las mujeres, quizá porque piense que, será expulsado como hacían las Amazonas con los hombres cuando ellas gobernaban. Ahora preguntémonos, ¿por qué dentro de la serie de dibujos animados solo hay una mujer entre los superamigos?, ¿por qué ha permanecido la Mujer Maravilla? 


\begin{tabular}{|c|c|c|c|}
\hline (2)inemito & Pstereolijus subrertibio & Caracteristicas & Resulladio \\
\hline $\begin{array}{l}\text { Escomponte } \\
\text { perinola } \\
\text { (Carmen Lyra) }\end{array}$ & $\begin{array}{l}\text { La mujer enfrenta al } \\
\text { hombre; lo despide de } \\
\text { sus dominios. }\end{array}$ & $\begin{array}{l}\text { Orgullosa, } \\
\text { altanera, } \\
\text { mal geniosa }\end{array}$ & $\begin{array}{l}\text { Silenciada con la autoridad } \\
\text { de la Ley de Dios. Se le } \\
\text { permite al hombre hacer } \\
\text { uso de la violencia, para } \\
\text { dominar a la mujer y a los } \\
\text { hijos. }\end{array}$ \\
\hline $\begin{array}{l}\text { El Rey Picodeloro } \\
\text { (Hnos. Grimm) }\end{array}$ & $\begin{array}{l}\text { La mujer dice la verdad } \\
\text { a cada pretendiente y } \\
\text { los rechaza en contra de } \\
\text { la voluntad de su padre. }\end{array}$ & $\begin{array}{l}\text { Orgullosa, altanera. } \\
\text { Hacía uso de la palabra. }\end{array}$ & $\begin{array}{l}\text { Silenciada y puesta a } \\
\text { padecer trabajos, con el } \\
\text { fin de que extrañe la vida } \\
\text { contemplativa. El propio } \\
\text { padre la obsequia. }\end{array}$ \\
\hline $\begin{array}{l}\text { Cucarachita } \\
\text { Mandinga y sus dos } \\
\text { novios } \\
\text { (Carlos L. Sáenz) }\end{array}$ & $\begin{array}{l}\text { Toma la decisión de } \\
\text { tener más de un novio y } \\
\text { poder escoger. }\end{array}$ & $\begin{array}{l}\text { No sirve para cocinera. } \\
\text { Imperfecta en las } \\
\text { labores domésticas. }\end{array}$ & $\begin{array}{l}\text { Los novios la abandonan, } \\
\text { porque lo que ella hace } \\
\text { está mal hecho. }\end{array}$ \\
\hline $\begin{array}{l}\text { El Rey que deseaba } \\
\text { escribir un cuento } \\
\text { (Lara Ríos) }\end{array}$ & $\begin{array}{l}\text { Se preocupa por el } \\
\text { pueblo. } \\
\text { Da su opinión. }\end{array}$ & $\begin{array}{l}\text { Esposa prudente y } \\
\text { sabia. } \\
\text { Hija preciosa y buena. }\end{array}$ & $\begin{array}{l}\text { Es silenciada. La ponen } \\
\text { a trabajar en labores } \\
\text { domésticas. No debe } \\
\text { ocupar el poder. La } \\
\text { palabra es del hombre. }\end{array}$ \\
\hline
\end{tabular}

¿Existen cuentos que rompen con esos estereotipos? Sí los hay. Dentro de esta caracterización de estereotipos, cobra importancia la intuición. La mujer y los niños no pierden la intuición aunque subviertan el orden establecido, porque "con una acusada naturaleza intuitiva suelen experimentar un considerable sufrimiento en las etapas de su vida...su naturaleza salvaje se revela muy pronto. Son niñas y niñas muy curiosos y astutos y ponen de manifiesto unas excentricidades que, debidamente desarrolladas, constituyen la base de su creatividad durante el resto de sus vidas" (Pinkola, 2003 p. 162).

Caso particular es el de la niña Filomena, personaje del cuento escrito por Alfonso Chase, Esta es la historia de Filomena, la niña que en Coris de Cartago, sostuvo al mundo:

una chiquilla como de ocho años, que vivía en Coris de Cartago y que era servicial, dulce y amable con los ancianos y los animales, y cada día sembraba un árbol, porque los quería mucho y le gustaba que dieran sombra al ganado y a los niños y que los pajarillos hicieran nido en las ramas... y Filomena gustaba de jugar con los niños...porque en el juego encontraba la alegría de los otros niños. 
Ella quería mucho a esos animales que se comen a los malos insectos y hacen gorgoritos en el jardín y que aunque son muy feos, son. como esas personas de cara fea pero con un inmenso corazón. (Chase,1992 p. 34).

Gracias a Filomena, Dios no castiga al mundo, pero la pone a prueba: la enferma, le salen escamas, queda huérfana y ciega. Sin embargo, como el Patito Feo del cuento de Andersen, Filomena es símbolo de la naturaleza salvaje y dado que las circunstancias la obligan, pasa penurias; se esfuerza instintivamente en seguir adelante, ocurra lo que ocurra, porque en la mujer y los niños, la perseverancia es una cualidad.

Esta niña-mujer no ha hecho nada más que ser ella misma y eso es comportarse de manera diferente. Si no se asemeja a los demás, la abuchean, la ponen a prueba, la tratan de matar, la aíslan, como el patito feo. Al final, ella gana, no cambia; es la que es. Por eso, sostuvo al mundo.

La mujer puede ser una cenicienta; no importa; pero como la niña Efigenia, del relato De cómo en Cartago también tuvimos nuestra Cenicienta, también de Chase. Ella leía, sabía escuchar historias, es decir, sabía de historia, actuó por instinto porque ella misma así lo quiso; no tuvo una madrina a la par, pero sí un buen ejemplo: Pancha Carrasco. Efigenia supo tomar decisiones y así "ella sacará de sí una luz nueva y escondida acumulada desde la infancia."

Mencionamos anteriormente, que los niños también son parte del mundo marginal y estereotipado impuesto por el patriarcalismo; pero también son capaces de subvertir; el cuento Queremos jugar, del autor Carlos Rubio, es una muestra de ello. Son los niños quienes deciden defenderse del poder impuesto y hacen una huelga, para poder jugar. Los encabeza la pequeña Ángela:

-Ángela impone su voz y convence a los niños de defender sus derechos "Vean lo que hicieron estos señores-les dijo señalándoles la fotografía de un grupo de gente que sostenía una pancarta. Ellos reclaman sus derechos. Hagamos nosotros lo mismo. Y se plantaron al día siguiente a la entrada del inmenso muro con grandes carteles que decían QUEREMOS JUGAR.

Ángela, al frente, hacían un gran escándalo con latas, juguetes y canoas viejas. Todos gritaban reclamando sus flores, sus pájaros y su luz. 


\begin{tabular}{|c|c|c|}
\hline Cuenio & 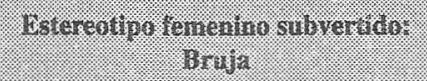 & Prueba \\
\hline $\begin{array}{l}\text { Esta es la historia de } \\
\text { Filomena, la niña que en } \\
\text { Coris de Cartago, sostuvo } \\
\text { al mundo }\end{array}$ & $\begin{array}{l}\text { una chiquilla como de ocho años, que } \\
\text { vivía en Coris de Cartago y que era } \\
\text { servicial, dulce y amable con los } \\
\text { ancianos y los animales, y cada dia } \\
\text { sembraba un árbol, porque los quería } \\
\text { mucho y le gustaba que dieran sombra } \\
\text { al ganado y a los niños y que los } \\
\text { pajarillos hicieran nido en las ramas...y } \\
\text { Filomena gustaba de jugar con los } \\
\text { niños...porque en el juego encontraba } \\
\text { la alegría de los otros niños. } \\
\text { Ella quería mucho a esos animales } \\
\text { que se comen a los malos insectos y } \\
\text { hacen gorgoritos en el jardín y que } \\
\text { aunque son muy feos, son como esas } \\
\text { personas de cara fea pero con un } \\
\text { inmenso corazón. }\end{array}$ & $\begin{array}{l}\text { Dios la pone la prueba y le ocasiona } \\
\text { sufrimiento físico } \\
\text { "Pero Filomena cayó enferma. Le } \\
\text { salieron unas escamas terribles por } \\
\text { todo el cuerpo" }\end{array}$ \\
\hline $\begin{array}{l}\text { De cómo en Cartago } \\
\text { también tuvimos nuestra } \\
\text { Cenicienta }\end{array}$ & $\begin{array}{l}\text { La niña Tinita era la que le prestaba los } \\
\text { libros a Efigenia y a veces, cuando } \\
\text { nadie las oía, le contaba historias de } \\
\text { amores secretos, de padres sin cabeza, } \\
\text { de mujeres terribles y bondadosas } \\
\text { como aquella doña Anacleta Arnesto o } \\
\text { de aquella otra señora, doña Pancha } \\
\text { Carrasco, que fue a la Guerra con las } \\
\text { Filibusteros, y que fumaba hojas de } \\
\text { chayote y hasta sabia empuñar el fusil". }\end{array}$ & $\begin{array}{l}\text { "Y, entonces, como si se le hubiera } \\
\text { metido un pequeño gusanillo, se empezó } \\
\text { a sentir muy inquieta y pensativa." } \\
\text { "De puro entusiasmada, se puso más } \\
\text { rígida, los hombros echados para } \\
\text { atrás y sin necesidad de colorete } \\
\text { estaba muy rosadota, muy llena de luz } \\
\text { como si la luna la bañara toda, como } \\
\text { si ella misma sacara de sí una luz } \\
\text { nueva y escondida, acumulada desde } \\
\text { la infancia." }\end{array}$ \\
\hline Queremos jugar & $\begin{array}{l}\text { Ángela impone su voz y convence a } \\
\text { los niños de defender sus derechos } \\
\text { "Vean lo que hicieron estos señores- } \\
\text { les dijo señalándoles la fotografía de } \\
\text { un grupo de gente que sostenía una } \\
\text { pancarta. Ellos reclaman sus } \\
\text { derechos. Hagamos nosotros lo } \\
\text { mismo. Y se plantaron al día } \\
\text { siguiente a la entrada del inmenso } \\
\text { muro con grandes carteles que } \\
\text { decían QUEREMOS JUGAR. } \\
\text { Ángela, al frente, hacían un gran } \\
\text { escándalo con latas, juguetes y } \\
\text { canoas viejas. Todos gritaban } \\
\text { reclamando sus flores, sus pájaros y } \\
\text { su luz". }\end{array}$ & $\begin{array}{l}\text { La ley representada por el poder } \\
\text { extranjero, la autoridad escolar y los } \\
\text { padres de familia. } \\
\text { "A ustedes. les debería dar verguienza } \\
\text { y tendrían que estar agradecidos con } \\
\text { ellos. Lo que están haciendo es un } \\
\text { atentado contra el progreso. -Si } \\
\text { continúan con esta juerga sus notas } \\
\text { escolares serán rebajadas". }\end{array}$ \\
\hline
\end{tabular}

¿Por qué la mujer debe ser ángel o demonio? ¿Cómo debe ser la relación entre hombre y mujer? Primero que todo, y como dice Emilia Macaya, situar a la mujer en esos puntos antagónicos es privarla de que hay un mundo real, cotidiano donde puede participar como ser humano; donde la relación entre mujer y hombre sea de tú a tú, sin ningún extremo. 
La literatura me hace sentir que el mundo en que vivo y cambiante está ahí, a punto de que lo descubra. Si la mujer es perversa, malcriada, orgullosa, bruja, y otras cosas más cuando se autodefine, prefiero ser considerada así, antes de cobarde, sumisa, callada. Las primeras conocen el mundo, son libres, opinan; saben escuchar historias como Efigenia y son activistas como Ángela. Las segundas, tienen el mundo acomodado. A las primeras, las desprecian porque son distintas; las otras son aceptadas por el resto de la sociedad, pero silenciada su voz y con la mirada baja, como la princesa del cuento "El rey Picodeloro" o aquella que aparece en el cuento "La negra y la rubia" de Carmen Lyra.

para su cuarto, sacó la arquita y preguntó a su consejera. Esta le dijo que aceptara, pero que eso sí, no debía alzar a ver al príncipe sino hasta que el padre les echara la bendición (Lyra, p. 102). la rubia, de Carmen Lyra:

Le propuso allí mismo matrimonio, pero ella quiso antes ir a con-
La literatura nos hace sentir que el mundo vivo y cambiante está ahí, a punto de que lo descubra. Si la mujer es la perversa, malcriada, orgullosa, bruja, y otras cosas más cuando se autodefine, prefiero ser considerada así, antes de cobarde, sumisa, callada. Las primeras conocen el mundo, son libres, opinan; saben escuchar historias como Efigenia y son activistas como Ángela. Las segundas, tienen el mundo acomodado. A las primeras, las desprecian porque son distintas; las otras son aceptadas por el resto de la sociedad, pero silenciada su voz y con la mirada baja, como la princesa del cuento El rey Picodeloro o aquella que aparece en el cuento La negra y sultar con su muñequita. Se fue

¿Cuáles son los papeles que desempeñan cada una de las mujeres que comparten con nosoras? ¿Cómo exige un hombre que se comporte una mujer? Habrán cambiado los estereotipos femeninos y masculinos que muy claramente nos presentan los cuentos? ¿Seguimos propiciando como personas los estereotipos? ¿Se está dando la inversión tanto en los cuentos como en nuestras vidas? La respuesta la tiene cada uno de nosotros y nosotras. No caigamos en extremos, simplemente busquemos la equidad.

La lectura de cuentos infantiles y de toda la literatura sirve para movernos y conmovernos como lectores; para que nos marque, porque nos interpela ¿Por qué será que las personas se aterrorizan cuando las miran directamente a los ojos? ¿Por qué ríe la Medusa?

La Medusa no muere: su sangre es capaz de quitar y dar la vida. La Medusa infunde respeto. La Medusa es feminidad. 
Por último, no importa si el cuento es escrito por un hombre o una mujer; lo que importa es cómo son sus personajes y la construcción social a la que se ven sometidos. Hablar de feminidad no es hablar de mujeres. Es hablar de una construcción social que puede estar presente en el hombre también. Quedan muchos cuentos, porque gracias s Dios, hay cuentos que contar. Ellos juegan con sus lectores y transmiten una sabiduría, sabiduría por lo demás ancestral.

\section{Referencias}

Calvo, Y. (2002) Literatura, mujer y sexismo. Editorial Universidad Nacional, Heredia, Costa Rica

Chase, Alfonso (1992) Fábula de fábulas. Editorial Costa Rica, San José

Gilbert, S. y Susan G. (1984). The madwoman in the attic. NineteenthCentury Literay Imagination, Yale University.

Lyra, C. (1997) Los cuentos de mi Tía Panchita. Educa. San José, Costa Rica.

Macaya, E. (1997). Espíritu en carne altiva. Editorial Universidad de Costa Rica. San José.

Pinkola Estés, C. (2003). Mujeres que corren con los lobos. Punto de lectura. Madrid. España.

Ríos, L. (1986). El rey que deseaba escribir un cuento. Ministerio de Cultura, Juventud y Deporte. San José, Costa Rica.

Rubio, Carlos (2001). Por la tierra de las hadas. Editorial URUK, San José, Costa Rica.

Rubio, C. (1990). Queremos jugar. Editorial Norma, San José, Costa Rica.

http://www.estudiosonline.net/texts/moraza.html) 